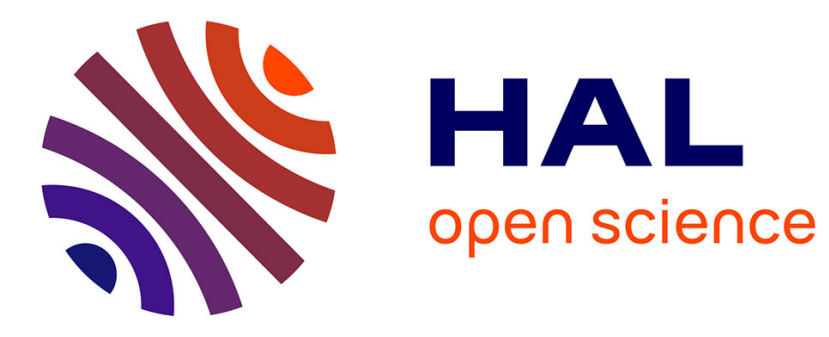

\title{
Regional variations of childhood immunisations in Senegal: a multilevel analysis
}

Sébastien Cortaredona, Rokhaya Diop, Valérie Seror, Luis Sagaon-Teyssier, Patrick Peretti-watel

\section{- To cite this version:}

Sébastien Cortaredona, Rokhaya Diop, Valérie Seror, Luis Sagaon-Teyssier, Patrick Peretti-watel. Regional variations of childhood immunisations in Senegal: a multilevel analysis. Tropical Medicine \& International Health, 2020, 25 (9), pp.1122-1130. 10.1111/tmi.13455 . hal-03160963

\section{HAL Id: hal-03160963 https://hal-amu.archives-ouvertes.fr/hal-03160963}

Submitted on 18 May 2021

HAL is a multi-disciplinary open access archive for the deposit and dissemination of scientific research documents, whether they are published or not. The documents may come from teaching and research institutions in France or abroad, or from public or private research centers.
L'archive ouverte pluridisciplinaire HAL, est destinée au dépôt et à la diffusion de documents scientifiques de niveau recherche, publiés ou non, émanant des établissements d'enseignement et de recherche français ou étrangers, des laboratoires publics ou privés. 


\title{
Regional variations of childhood immunisations in Senegal: a multilevel analysis
}

\author{
Sébastien Cortaredona ${ }^{1,2}$, Rokhaya Diop ${ }^{3}$, Valérie Seror ${ }^{1,2}$, Luis Sagaon-Teyssier ${ }^{4}$ and Patrick Peretti-Watel ${ }^{1,2,5}$ \\ 1 Aix Marseille University,IRD, AP-HM, SSA, VITROME, Marseille, France \\ 2 IHU-Méditerranée Infection, Marseille, France \\ 3 National School of Statistics and Economic Analysis, Dakar, Senegal \\ 4 Aix Marseille University,INSERM, IRD, SESSTIM, Marseille, France \\ 5 ORS PACA,Southeastern Health Regional Observatory, Marseille, France
}

\begin{abstract}
objectives To estimate geographical variations of child immunisation at the regional level in Senegal, to identify individual and contextual factors that could explain these regional discrepancies, and to measure their effects.

METhods Data come from the 2015, 2016 and 2017 Senegalese Demographic and Health Survey, a national survey targeting women aged $15-49$, with a questionnaire focusing on health and reproductive issues including their children's immunisation status. We restricted the analysis to children aged 12-23 months $(n=4955)$ and conducted a multilevel logistic regression to assess individual and contextual factors associated with complete immunisation coverage.

RESULTS The complete immunisation coverage rate of children was estimated at $68 \%$ and ranged from $41 \%$ in the region of Kedougou to $83 \%$ in the region of Dakar. The inter-regional variance was significantly different from zero $(P=0.006)$ in the empty multilevel model. It decreased by more than half $(57 \%)$ after adjusting for individual factors but remained significantly different from zero $(P=0.010)$. Regional variations of complete immunisation rates drastically decreased and were no longer statistically significant $(P=0.343)$ after adjusting for the following regional factors: population density, density of hospitals, literacy rate and proportion of health facilities with an antenatal care service.

CONCLUSIONS Regarding health policies designed to improve childhood immunisation and to reduce related inequalities, our results highlight the need to take into account both individual and contextual factors, with a focus on rural and deprived areas where children are at higher risk of incomplete immunisation.
\end{abstract}

keywords childhood vaccination, coverage, immunisation, socioeconomic, Senegal

Sustainable Development Goals (SDGs): SDG 3 (good health and well-being), SDG 4 (quality education), SDG 10 (reduced inequalities), SDG 17 (partnerships for the goals)

\section{Introduction}

In sub-Saharan African countries, where vaccine-preventable diseases are the major contributors to child mortality (74 per 1000 live births), childhood immunisation remains one of the most cost-effective preventive strategies against mortality and morbidity among children [1]. Following WHO efforts to prevent childhood diseases, Senegal launched its Expanded Programme on Immunization (EPI) in 1979. Thanks to EPI, vaccines are routinely provided free of charge in public health facilities and during mass immunisation campaigns. Door-to-door activities are regularly implemented across the country to help increase child immunisation uptake across all regions of
Senegal. In addition to maintaining high coverage rates, another priority goal is reducing social inequalities in child vaccination uptake, as Senegalese authorities endorsed the Global Vaccine Action Plan (GVAP) aiming at 'extending by 2020 and beyond the full benefits of immunization to all people, regardless of where they are born, who they are, or where they live' [2].

After decades of implementation, EPI continues to achieve very significant results in improving children's vaccination uptake in Senegal, which rose from $70 \%$ to $75 \%$ between 2012 and 2017 [3]. Despite such efforts, it is nevertheless a struggle to maintain high vaccination uptake rates across all regions of Senegal. Data from the 2017 Demographic and Health Survey (DHS) showed that rates 
of complete immunisation of children aged 12-23 months ranged from $34 \%$ in the region of Kédougou to $85 \%$ in the region of Dakar [3]. Likewise, a secondary analysis of the 2011 DHS [4] showed that children living in eastern regions of Senegal were significantly less likely to be fully vaccinated than children living in western regions (OR: $0.6295 \%$ CI (0.39-0.97)). Regional differences were also found when it came to vaccinations being administered at the right time [5]. However, these studies did not address whether regional differences in child immunisation rates could be attributable to differences in population characteristics (socioeconomic level, ethnicity, etc.) or whether these disparities referred to differences in quantity and/or quality of healthcare services between the administrative regions. As a result, the question addressed in this paper was whether the effects of contextual socioeconomic factors (such as poverty index and literacy rate) were likely to persist after adjustment for individual-level socioeconomic characteristics (such as mother's education level and household wealth index), indicating an independent influence of area deprivation on child immunisation. Using data from the 2015-2017 Demographic and Health Survey (DHS) $[3,6,7]$ which is conducted annually by the Senegalese National Agency for Statistics and Demographics (ANSD) in addition to the regional reports on the economic and social conditions of all regions of Senegal [8], this study aimed at assessing the relative effects of individual factors and contextual factors on child immunisation.

\section{Methods}

\section{Data}

The Senegalese National Agency for Statistics and Demographics (ANSD) carries out nationally representative household surveys $[3,6,7]$ and health facility assessments [9]. Our data were drawn from the DHS exercises carried out in Senegal in 2015, 2016 and 2017 [3,6,7], and downloaded from the DHS programme website (dhsprogram.com). These surveys involved a two-stage data collection process. At the first stage, the primary sampling units (PSUs), which were the census districts, were selected with probability proportional to the PSU population size. At the second stage, households were selected and enumerated within each area segment. The samples were stratified by urban and rural areas. In total, 4706, 4500 and 8800 occupied households were selected for the 2015, 2016 and 2017 DHS, respectively, with response rates of $99 \%, 99 \%$ and $92 \%$, respectively. One questionnaire focussed on women aged 15 to 49 years at the time of the survey [8], with a set of questions examining immunisation coverage of their children under five.

\section{Study population}

As in previous studies devoted to childhood vaccination in various sub-Saharan African countries [3,4,7,10-14], we restricted the analysis to children aged between 12 and 23 months at the time of the surveys $(n=1295$, 1306 and 2354 for DHS 2015, 2016 and 2017, respectively). Combining the three DHS increased the sample size and enabled us to estimate regional variations of child immunisation with more accuracy.

\section{Measurement of variables}

A binary 'complete immunisation' variable was built whose modalities were coded 1 for children who received the five vaccines recommended before 24 months of age (a single shot for BCG, measles and yellow fever vaccines, and three shots for pentavalent and polio vaccines), and 0 otherwise. We relied on two different sources of information regarding children's vaccination status: the vaccination card shown by mothers to interviewers or mothers' recall of vaccination if the card was missing.

Regarding individual factors associated with immunisation status, the following factors were considered based on previously published studies [4,12,14-16]: the child's characteristics (sex, age in months and birth order), mother's characteristics (age at childbirth, education level and ethnic group) and household's characteristics (wealth index). The household wealth index is a composite measure of a household's cumulative living standard (taking into account materials used for housing construction, access to sanitation facilities, ownership of television, bicycle, etc.) [17].

Variables on the use of healthcare services, such as the place of delivery (home/health facility), antenatal care during pregnancy, and postnatal check-ups within three months, were also retrieved from the DHS database. Regarding the geographical localisation of children, we used the region of residence at the time of the survey. We chose to work at the regional level because most contextual variables are available at this administrative level [13]. Senegal is subdivided into 14 regions.

For contextual (regional) variables, we retrieved the following variables from the ANSD reports on the economic and social conditions of regions [13]: population density in 2016, poverty index (proportion of the population that lives in poverty) and literacy rate in 2011. We also retrieved the following healthcare variables from the Service Provision Assessment (SPA) survey carried out in Senegal in 2016 [9]: density of hospitals/health centres/ healthcare staff/general practitioners, proportion of health facilities with an antenatal care service/vaccination service. 


\section{Statistical analysis}

In the DHS, the sample is selected with unequal probability to expand the number of cases available for certain areas or subgroups for which statistics are needed. Thus, sampling weights were applied to all statistics to produce the correct representation as well as corrections for differential response rates for certain areas or subgroups. We used a Spearman rank correlation coefficient to identify contextual factors associated with child immunisation rates at the regional level. Multilevel modelling made it possible to test for associations between the probability of complete immunisation and individual-level variables (level 1) and, independent of the latter, the characteristics of the regions (level 2). First, a 'null' multilevel logistical model (model without any covariate) was tested to verify the significance of the inter-region and the inter-survey (DHS 2015, 2016 and 2017) variabilities. We then performed a multilevel model adjusted on individual variables and a third model adjusted on both individual and regional variables. If several regional variables were strongly linked (such as the proportion of healthcare facilities with an antenatal care service and the proportion of healthcare facilities with a vaccination service), then all could be considered as 'proxies' of the same phenomenon, and a single variable was selected to avoid issues of multicollinearity and model convergence. All regional variables were selected using a backward selection $(P<0.05$ to stay within the model). We used the median odds ratio (MOR) and the proportional change in variance $(\mathrm{PCV})$ to quantify the inter-region variability [18]. All analyses were based on two-sided $P$-values, with statistical significance defined by $P \leq 0.05$. They were performed using SAS 9.4 statistical software (SAS Institute, Cary, NC). Maps were produced using the QGIS software [19].

\section{Ethical approval}

Ethical approval was granted by the Ethics Committee of the National Statistical Office of Senegal.

\section{Results}

\section{Study population characteristics}

The study population comprised 4955 children (1295, 1306 and 2354 from the 2015, 2016 and 2017 DHS, respectively, Table 1$)$. The mean age of the study population was 17.5 months $(\min =12$; $\max =23)$, and the sex ratio was close to one ( $51 \%$ males). Regarding the characteristics of the children's mothers, $56 \%$ were aged under 30 when the child was born, 96\% attended antenatal care and $86 \%$ had at least one postnatal check-up within three months after the child's birth.

\section{Complete immunisation coverage rate and bivariate analyses}

Overall, the complete immunisation coverage rate of children was estimated at $68 \%$. It ranged from $41 \%$ in the region of Kedougou to $83 \%$ in the region of Dakar (Figure 1). The coefficient of variation of the complete immunisation coverage rate was estimated at $19 \%$ : higher coverage rates were observed in the western and northern regions of the country, whereas the lowest values were observed in the eastern and southeastern regions.

Regarding associations with contextual variables, Table 2 shows that population density $(\rho=0.78$, $P=0.001)$, density of hospitals $(\rho=0.56, P=0.039)$ and literacy rate $(\rho=0.88, P<0.001)$ were significantly and positively correlated with the regional complete immunisation coverage rate.

\section{Multilevel modelling}

The empty (null) multilevel model indicated an inter-regional variance that was significantly different from zero $(\sigma=0.32, P=0.006$; Table 3$)$ and an inter-survey variance that was not statistically significant $(\sigma=0.002$, $P=0.350$; Table 3 ). A likelihood ratio test indicated that this model provided a better fit than an empty model without any random effect $(P<0.001)$, and thus justified the multilevel approach.

Inter-regional variance decreased to $0.14(-57 \%)$ after introducing the individual variables but remained significantly different from zero $(P=0.010)$. Regarding the children's characteristics, age was positively correlated with complete immunisation. Regarding the mothers' characteristics, the probability of complete immunisation was higher among the oldest mothers (those who were over the age of 30 when the child was born), more educated mothers, those who gave birth in a healthcare facility, and those who attended antenatal care, as well as among those who had at least one postnatal check-up. Compared to the Wolof ethnic group (either Puular or Manding), belonging to a minority ethnic group was negatively correlated with complete immunisation.

The full model, adjusted for both individual and contextual variables, confirmed some of the above-mentioned bivariate associations (Table 2). The probability of complete immunisation was significantly higher in regions 
Table I Study population characteristics (DHS 2015-2017, $n=4955$ )

\begin{tabular}{|c|c|c|c|c|}
\hline & DHS 2015 & DHS 2016 & DHS 2017 & All \\
\hline & $n=1295$ & $n=1306$ & $n=2354$ & $n=4955$ \\
\hline & $\% *$ & $\% *$ & $\% *$ & $\% *$ \\
\hline Age of the child at interview in months-mean(SD) & $17.4(3.1)$ & $17.4(3.2)$ & $17.6(3.3)$ & $17.5(3.2)$ \\
\hline \multicolumn{5}{|l|}{ Sex of the child } \\
\hline Male & 49.8 & 50.5 & 51.6 & 50.9 \\
\hline Female & 50.2 & 49.5 & 48.4 & 49.1 \\
\hline \multicolumn{5}{|l|}{ Birth order } \\
\hline First child & 20.0 & 25.7 & 23.6 & 23.2 \\
\hline Second child & 20.0 & 15.8 & 19.4 & 18.6 \\
\hline Higher & 60.0 & 58.5 & 57.0 & 58.2 \\
\hline \multicolumn{5}{|l|}{ Mother's age when the child was born } \\
\hline $15-19$ & 5.4 & 8.2 & 6.6 & 6.7 \\
\hline $20-29$ & 54.6 & 48.2 & 46.2 & 48.9 \\
\hline $30+$ & 40.0 & 43.6 & 47.2 & 44.4 \\
\hline \multicolumn{5}{|l|}{ Mother's education level } \\
\hline No education & 67.8 & 65.4 & 60.0 & 63.4 \\
\hline Primary & 19.6 & 21.4 & 22.2 & 21.3 \\
\hline Secondary or higher & 12.6 & 13.2 & 17.8 & 15.3 \\
\hline \multicolumn{5}{|l|}{ Mother's ethnic group } \\
\hline Wolof & 40.5 & 41.5 & 36.1 & 38.6 \\
\hline Puular & 29.7 & 31.4 & 28.4 & 29.5 \\
\hline Serer & 13.2 & 15.6 & 18.0 & 16.2 \\
\hline Manding & 4.8 & 4.8 & 6.2 & 5.5 \\
\hline Other & 11.7 & 6.6 & 11.3 & 10.2 \\
\hline \multicolumn{5}{|l|}{ Household wealth quintile } \\
\hline Poorest & 25.2 & 26.6 & 24.3 & 25.1 \\
\hline Poorer & 23.8 & 25.2 & 22.1 & 23.3 \\
\hline Middle & 18.0 & 17.3 & 19.7 & 18.7 \\
\hline Richer & 17.8 & 14.5 & 16.4 & 16.2 \\
\hline Richest & 15.2 & 16.5 & 17.6 & 16.7 \\
\hline \multicolumn{5}{|l|}{ Place of delivery } \\
\hline At health facility & 73.8 & 75.4 & 79.2 & 76.8 \\
\hline Home & 26.2 & 24.6 & 20.8 & 23.2 \\
\hline \multicolumn{5}{|l|}{ Mother attended antenatal care } \\
\hline No & 5.6 & 4.9 & 3.3 & 4.3 \\
\hline Yes & 94.4 & 95.1 & 96.7 & 95.7 \\
\hline \multicolumn{5}{|l|}{ Postnatal check-up within 3 months } \\
\hline No & 15.5 & 12.9 & 13.7 & 14.0 \\
\hline Yes & 84.5 & 87.1 & 86.3 & 86.0 \\
\hline
\end{tabular}

*Unless otherwise stated.

with a high density of hospitals, a high literacy rate and in regions with a high proportion of healthcare facilities with an antenatal care service (Table 3). Compared to regions with low population density, the probability of complete immunisation was significantly higher in regions with intermediate population density (OR 95\% CI: 1.42 $1.12-1.81$ ) but it was not statistically different in regions with high population density (OR 95\% CI: $0.990 .76-$ 1.29). After introducing these four regional variables to the model, the inter-regional variance decreased to 0.003 $(-98 \%)$ and was no longer significantly different from zero $(P=0.343)$. The MOR was close to one $(1.05)$, which indicated that the residual heterogeneity between regions in the median case increased by just 1.05 times the individual odds of complete immunisation when randomly picking out two children within two different regions (see Figure S1 for maps of regional random effect estimates with statistical significance). 


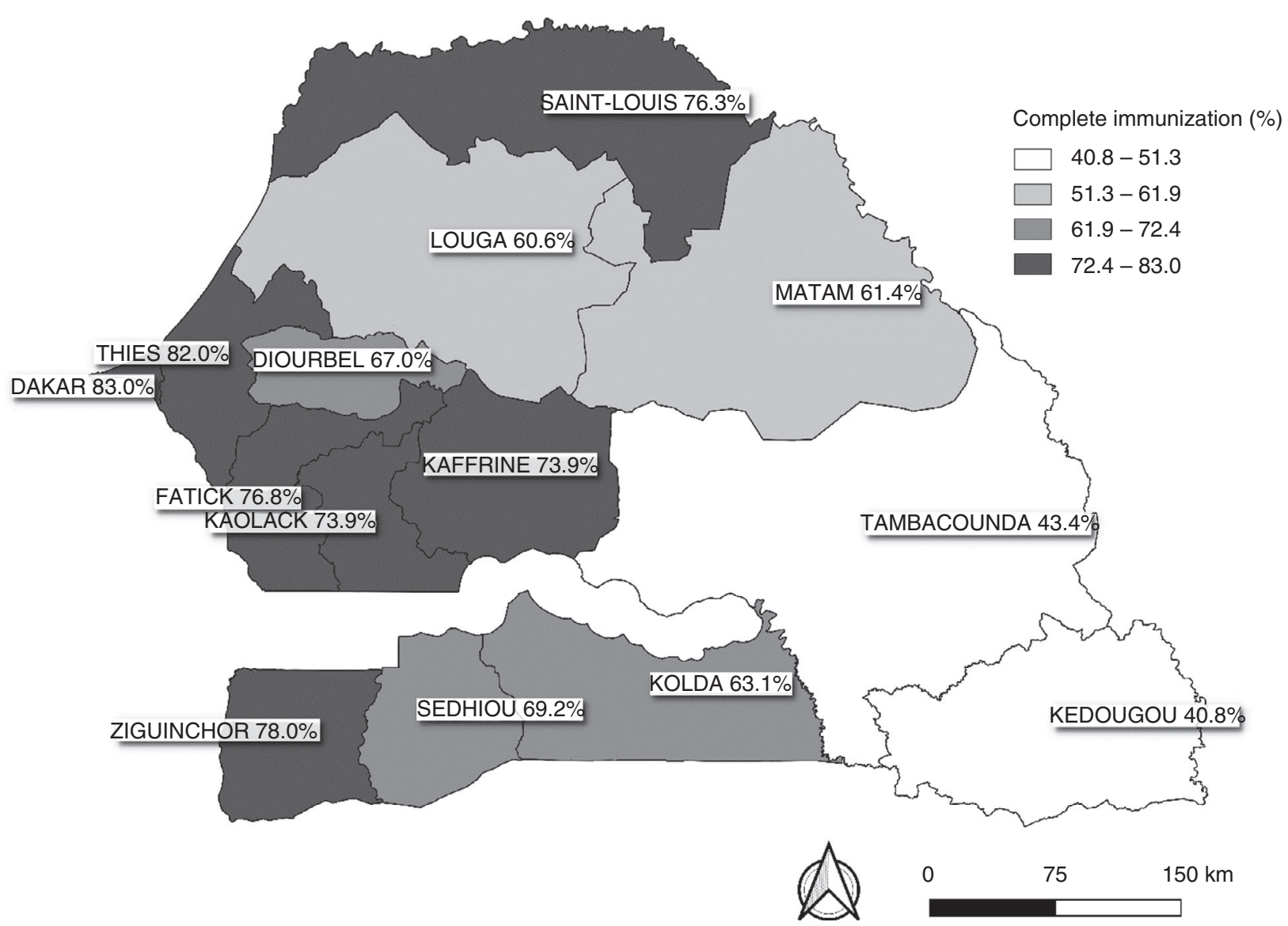

Figure I Complete immunisation of children aged 12-23 months at the time of the interview (DHS 2015-2017, $n=4955$ ). Mean: $67.9 \%$, Max: $83.0 \%$ (Dakar), Min: $40.8 \%$ (Kédougou), Coefficient of variation: $19.2 \%$.

\section{Discussion}

Summary of the main results

Using data from the Senegalese Demographic and Health Survey (DHS), our study revealed large inter-regional variations in child immunisation. These variations drastically decreased after adjusting for individual factors (age of the child, mother's age/education level/ethnicity, place of delivery, use of antenatal care and postnatal check-up) and especially contextual factors (population density, density of hospitals, literacy rate and proportion of healthcare facilities with an antenatal service), which were significantly associated with complete child immunisation.

\section{Individual determinants of childhood vaccination}

Children from mothers who attended antenatal care, those who gave birth in a healthcare facility or who had postnatal check-up were found to be more likely to be fully vaccinated. While similar associations were found in previous studies in Senegal $[4,14]$, in other sub-Saharan African countries [12,20], and more generally in lowand middle-income countries [21], our study showed that adjusting for these factors drastically decreased the interregional variations of complete immunisation observed in the empty model. It is, however, worth noting that individual factors such as attending antenatal care and postnatal check-ups could relate to both supply side (availability and accessibility of healthcare services) and demand-side (maternal attitude toward pre-/postnatal care) effects. Our study showed that these effects persist after adjusting for variables that strictly quantify the supply of health care on the regional level (density of hospitals, healthcare services with an antenatal service).

Furthermore, the present study confirmed the wellknown effects of mother's educational level $[4,5,12,15,22-25]$ and, to a lesser extent, mother's age 
Table 2 Regional contextual variables $(n=14)$

\begin{tabular}{|c|c|c|c|c|c|c|c|}
\hline & & Mean (SD) & Min & & Max & & $\begin{array}{l}\text { Spearman's rank } \\
\text { correlation coefficient* }\end{array}$ \\
\hline \multirow[t]{3}{*}{$\begin{array}{l}\text { Sociodemographic } \\
\text { variables }\end{array}$} & $\begin{array}{l}\text { Population density (hbts/ } \\
\left.\mathrm{km}^{2}\right) \dagger\end{array}$ & $543.5(1651.2)$ & 9.9 & Kedougou & 6269.4 & Dakar & $\begin{array}{l}0.78 \\
P=0.001\end{array}$ \\
\hline & Poverty index $(\%) \ddagger$ & $54.7(16.6)$ & 26.1 & Dakar & 76.6 & Kolda & $\begin{array}{l}-0.30 \\
P=0.296\end{array}$ \\
\hline & Literacy rate $(\%) \ddagger$ & $45.7(11.7)$ & 28.4 & Matam & 68.6 & Dakar & $\begin{array}{l}0.88 \\
P<0.001\end{array}$ \\
\hline \multirow[t]{6}{*}{$\begin{array}{l}\text { Health care } \\
\text { variables }\end{array}$} & $\begin{array}{l}\text { Density of hospitals per } \\
100000 \mathrm{hbt}^{\S}\end{array}$ & $0.3(0.2)$ & 0.0 & Kedougou & 1.0 & Dakar & $\begin{array}{l}0.56 \\
P=0.039\end{array}$ \\
\hline & $\begin{array}{l}\text { Density of healthcare } \\
\text { centres per } 100000 \mathrm{hbts}^{\S}\end{array}$ & $1.1(0.6)$ & 0.4 & Diourbel & 2.4 & Tambacounda & $\begin{array}{l}-0.26 \\
P=0.366\end{array}$ \\
\hline & $\begin{array}{l}\text { Density of healthcare posts } \\
\text { per } 100000 \mathrm{hbts}^{\S}\end{array}$ & $12.2(4.2)$ & 5.9 & Diourbel & 20.9 & Ziguinchor & $\begin{array}{l}0.06 \\
P=0.840\end{array}$ \\
\hline & $\begin{array}{l}\text { Density of general } \\
\text { practitioner per } 100000 \\
\text { hbts }^{\S}\end{array}$ & $5.6(5.3)$ & 0.8 & Louga & 17.2 & Sedhiou & $\begin{array}{l}-0.08 \\
P=0.782\end{array}$ \\
\hline & $\begin{array}{l}\text { Proportion of healthcare } \\
\text { facilities with an } \\
\text { antenatal care service } \\
(\%)^{\S}\end{array}$ & $89.5(8.4)$ & 73.1 & Kolda & 100.0 & Matam & $\begin{array}{l}-0.13 \\
P=0.637\end{array}$ \\
\hline & $\begin{array}{l}\text { Proportion of healthcare } \\
\text { facilities with a } \\
\text { vaccination service }(\%)^{\S}\end{array}$ & $86.7(11.0)$ & 59.5 & Kolda & 100.0 & Matam & $\begin{array}{l}-0.13 \\
P=0.659\end{array}$ \\
\hline
\end{tabular}

"Spearman's rank correlation coefficient with complete immunisation of children aged 12-23 months at the regional level (see Figure 1).

$\dagger$ Source: National Agency for statistic and demography (2016 data). $¥$ Source: National Agency for statistic and demography (2011 data). §Source: Service Provision Assessment (2016 data).

$[15,25]$ being positively correlated with complete immunisation of their children. Mother's ethnicity was also significantly associated with child immunisation, confirming findings of a systematic review of the published literature on the reasons for the under-vaccination of children in low- and middle-income countries: belonging to a minority ethnic or religious group was associated with undervaccination [21].

\section{Contextual determinants of childhood immunisation}

In order to fully grasp the relationship between education level and child immunisation, both individual (mother's education level) and contextual variables (literacy rate) were introduced to our model, as omitting either would result in model bias. Indeed, without individual-level information, the literacy rate may act partially or entirely as a proxy for individual characteristics. One of the most important findings of this study is that the contextual level of education has an independent effect on child immunisation, over and above the effect of the mother's level of education.
Regardless of the mother's level of education, children may have a higher risk of being incompletely immunised when they live in a less educated region than when they live in more educated one. It might be related to the education level of community health workers, who play an important role in the vaccination campaigns conducted by the health facilities and access to health care services in general [26].

A multilevel analysis of DHS data from 24 countries in sub-Saharan Africa [27] also provided evidence that unimmunised children born to mothers with no formal education and living in communities with high illiteracy rates were more likely to be unimmunised. This suggests that children in the same neighbourhood are subject to common contextual influences [18], thus, providing evidence of contextual phenomena shaping children's risk of being unimmunised.

The lower complete immunisation rates observed in the eastern regions of Senegal could be partially explained by the lower density of population, lower density of hospitals and the lower proportion of healthcare facilities with an antenatal service in these regions. Indeed, the eastern 
Table 3 Individual and contextual factors associated with complete immunisation of children aged 12-23 months - Multilevel logistic regressions (DHS 2015-2017, $n=4955$ )

\begin{tabular}{|c|c|c|c|}
\hline & $\begin{array}{l}\text { Empty model } \\
\text { OR } 95 \% \text { CI }\end{array}$ & $\begin{array}{l}\text { Individual model } \\
\text { OR } 95 \% \text { CI }\end{array}$ & $\begin{array}{l}\text { Full model } \\
\text { OR } 95 \% \text { CI }\end{array}$ \\
\hline Age of the child at interview* & & $1.101 .03-1.17$ & $1.101 .03-1.17$ \\
\hline \multicolumn{4}{|l|}{ Sex of the child (ref. female) } \\
\hline Male & & $1.040 .92-1.18$ & $1.040 .92-1.18$ \\
\hline \multicolumn{4}{|l|}{ Birth order (ref. 1) } \\
\hline 2 & & $0.910 .73-1.14$ & $0.900 .72-1.13$ \\
\hline $3+$ & & $0.940 .76-1.16$ & $0.930 .75-1.15$ \\
\hline \multicolumn{4}{|l|}{ Mother's age when the child was born (ref. 20-30) } \\
\hline $15-19$ & & $1.010 .77-1.33$ & $1.000 .76-1.31$ \\
\hline $30+$ & & $1.221 .05-1.42$ & $1.221 .05-1.42$ \\
\hline \multicolumn{4}{|l|}{ Mother's education level (ref. no education) } \\
\hline Primary & & $1.381 .16-1.65$ & $1.371 .15-1.64$ \\
\hline Secondary or higher & & $1.851 .46-2.33$ & $1.841 .46-2.33$ \\
\hline \multicolumn{4}{|l|}{ Mother's ethnic group (ref. wolof) } \\
\hline Puular & & $0.630 .52-0.75$ & $0.670 .56-0.80$ \\
\hline Serer & & $0.980 .77-1.26$ & $1.000 .78-1.28$ \\
\hline Manding & & $0.460 .35-0.60$ & $0.460 .36-0.59$ \\
\hline Other & & $0.540 .42-0.70$ & $0.530 .42-0.67$ \\
\hline \multicolumn{4}{|l|}{ Household wealth quintile (ref. middle } \\
\hline Poorest & & $0.940 .76-1.17$ & $0.920 .74-1.13$ \\
\hline Poorer & & $0.940 .77-1.15$ & $0.940 .77-1.14$ \\
\hline Richer & & $1.030 .81-1.32$ & $1.000 .78-1.28$ \\
\hline Richest & & $1.170 .85-1.60$ & $1.070 .78-1.47$ \\
\hline \multicolumn{4}{|l|}{ Place of delivery (ref. in a health facility) } \\
\hline At home & & $0.700 .59-0.82$ & $0.690 .59-0.81$ \\
\hline \multicolumn{4}{|l|}{ Mother attended antenatal care (ref. no) } \\
\hline Yes & & $2.001 .50-2.66$ & $1.991 .50-2.65$ \\
\hline \multicolumn{4}{|l|}{ Postnatal check-up within 3 months (ref. no) } \\
\hline Yes & & $1.561 .31-1.86$ & $1.551 .30-1.85$ \\
\hline Inter-survey variability estimate $-P-$ value $^{\dagger}$ & $0.002-P=0.350$ & & \\
\hline \multicolumn{4}{|l|}{ Population density $\left(\right.$ ref. $<\mathrm{Q}_{1}$ ) } \\
\hline Intermediate $\left(\mathrm{Q}_{1}-\mathrm{Q}_{3}\right)$ & & & $1.421 .12-1.81$ \\
\hline $\operatorname{High}\left(\mathrm{Q}_{1}-\mathrm{Q}_{3}\right)$ & & & $0.990 .76-1.29$ \\
\hline Density of hospitals* & & & $1.191 .02-1.39$ \\
\hline Literacy rate* & & & $1.311 .12-1.53$ \\
\hline Proportion of healthcare facilities with an antenatal care service* & & & $1.211 .10-1.32$ \\
\hline Inter-region variance estimate $-P$-value ${ }^{\ddagger}$ & $0.32-P=0.006$ & $0.14-P=0.010$ & $0.003-P=0.343$ \\
\hline Median odds ratio & 1.71 & 1.42 & 1.05 \\
\hline Proportional change in variance $(\%)$ & - & $-56.5 \%$ & $-98.1 \%$ \\
\hline Akaike information criterion & 5939 & 5700 & 5670 \\
\hline
\end{tabular}

*In order to compare odds ratios for predictors that were measured on different scales, all continuous predictors were standardised $($ mean $=0 ; \mathrm{SD}=1)$.

${ }^{\dagger}$ Random intercept for the three surveys (DHS 2015, 2016 and 2017). Since the effect was not statistically significant in the empty model, it was excluded from the individual and full models.

${ }^{*}$ Random intercept for the 14 regions.

regions of Senegal are rural regions while the western region is more urban. From a supply side perspective, access to immunisation services is usually more difficult to guarantee in rural areas, thus the effects of these variables may mediate the urban/rural opposition. Other studies in sub-Saharan Africa also showed that children living in rural areas or living a great distance from healthcare centres were at a higher risk of incomplete immunisation [28,29], given that poor access and distance from vaccination services is the most frequently 
reported reason for non- or under-vaccination of children in low- and middle-income countries [21].

\section{Limitations of the study}

A first limitation related to data collection, and more specifically to the use of mothers' recall of vaccination if the vaccination card was missing. Although mothers' recall might be subject to either recall bias or social desirability bias, in studies conducted in similar contexts it provided similar responses as information derived from vaccination cards [30,31]. A second limitation was to restrict the analysis to children aged 12-23 months although this age range was expected to minimise the length of recall required of the mothers (which is longer for older children). Another limitation related to some time-varying individual factors that were measured at the time of the survey, that is not at the time of vaccination. A final limitation refers to the possibility of biased estimates due to child mortality, since only living children were included in the study, bringing into question the issue of generalising the study to all children, living and deceased.

\section{Conclusion}

The complete immunisation rate among children aged between 12 and 23 months in Senegal ranges from 41\% to $83 \%$ across the regions and is still far below the goals of the GVAP [2] set by WHO and UNICEF, which recommended $90 \%$ national vaccination coverage and $80 \%$ vaccination coverage in every district or equivalent administrative unit. However, the complete immunisation rates in Senegal are still higher than those of other west African countries (51\% in Ivory Coast and 39\% in Mali) [32]. As regards inter-regional disparities, our results highlight the need to account for both individual and contextual factors, with a focus on rural and deprived areas where children are at higher risk of incomplete immunisation. This study shows a strong correlation between child immunisation and the supply of health care on the regional level. However, it does not allow us to deduce any direct cause-and-effect relationship between the density and quality of healthcare supply and child immunisation. Longitudinal or panel designs could offer a better understanding of the potential causal process between healthcare supply and child immunisation. However, improving access to health care for pregnant women could help enhance equity in child immunisation across the country. Initiatives such as the 'Reaching Every District strategy' $[4,33,34]$ should help improve the immunisation system and support low-performance regions.
Finally, because the mother's ethnicity was significantly associated with child immunisation even after adjusting for contextual factors, it is possible that local cultural features shape attitudes toward vaccination. Further research would be necessary to shed light on this issue.

\section{Declarations}

This study was made possible thanks to the DHS Program-Senegal. The DHS data are available to the general public upon request at the Measure DHS website [http:// www.dhsprogram.com]. We submitted a request to the DHS program by describing the purpose and objectives of the study and thereafter received permission to download the data set. This publication reflects the authors' views and not the views of UNICEF.

\section{References}

1. Maman K, Zöllner Y, Greco D, Duru G, Sendyona S, Remy V. The value of childhood combination vaccines: From beliefs to evidence. Hum Vaccines Immunother 2015: 11: 2132-2141.

2. World Health Organization. Global Vaccine Action Plan 2011-2020. 2013. (Available from: https://afro.who.int/sites/ default/files/2017-06/9789241504980_eng.pdf).

3. Agence Nationale de la Statistique et de la Démographie. Sénégal: Enquête Démographique et de Santé Continue (EDS-Continue) 2017. 2018. (Available from: http://www.a nsd.sn/ressources/rapports/Rapport \%20Final\%20EDS\% 202017.pdf)

4. Mbengue MAS, Sarr M, Faye A et al. Determinants of complete immunization among senegalese children aged 12-23 months: evidence from the demographic and health survey. BMC Public Health 2017: 17: 630.

5. Mbengue MAS, Mboup A, Ly ID et al. Vaccination coverage and immunization timeliness among children aged 12-23 months in Senegal: a Kaplan-Meier and Cox regression analysis approach. Pan Afr Med J 2017: 27(Suppl 3): 8.

6. Agence Nationale de la Statistique et de la Démographie. Sénégal: Enquête Démographique et de Santé Continue (EDS-Continue) 2015. 2016. (Available from: http://www.a nsd.sn/ressources/rapports/Rapport\%20EDS\%20Continue\% 202015.pdf)

7. Agence Nationale de la Statistique et de la Démographie. Sénégal : Enquête Démographique et de Santé Continue (EDS-Continue) 2016. 2017. (Available from: http://www.a nsd.sn/ressources/publications/EDS-C\%202016.pdf)

8. Rutstein SO, Rojas G.Guide to DHS statistics. 2006. (Available from: https://dhsprogram.com/pubs/pdf/DHSG1/Guide_ to_DHS_Statistics_29Oct2012_DHSG1.pdf).

9. Agence Nationale de la Statistique et de la Démographie. Sénégal: Enquête Continue sur la Prestation des Services de Soins de Santé (ECPSS). 2017. (Available from : http:// www.ansd.sn/ressources/publications/ECPSS\%202016.pdf) 
10. Ndiaye NM, Ndiaye P, Diédhiou A, Guèye AS, Tal-Dia A. Factors related to failure to complete immunization of children aged 10-23 months in Ndoulo (Senegal). Sante Montrouge Fr. 2009: 19: 9-13.

11. Fatiregun AA, Etukiren EE. Determinants of uptake of third doses of oral polio and DTP vaccines in the Ibadan North Local Government Area of Nigeria. Int Health 2014: 6: 213-224.

12. Lakew Y, Bekele A, Biadgilign S. Factors influencing full immunization coverage among 12-23 months of age children in Ethiopia: evidence from the national demographic and health survey in 2011. BMC Public Health 2015: 15: 728.

13. Agence Nationale de la Statistique et de la Démographie. Situation économique et sociale régionale 2016. 2019. (Available from: http://www.ansd.sn/ressources/ses/SES-Da kar-2016.pdf).

14. Peretti-Watel P, Cortaredona S, Ly EY et al. Determinants of childhood immunizations in Senegal: Adding previous shots to sociodemographic background. Hum Vaccines Immunother 2019: 16: 1-8.

15. Mutua MK, Kimani-Murage E, Ettarh RR. Childhood vaccination in informal urban settlements in Nairobi, Kenya: who gets vaccinated? BMC Public Health 2011: 11: 6.

16. Fatiregun AA, Okoro AO. Maternal determinants of complete child immunization among children aged 12-23 months in a southern district of Nigeria. Vaccine 2012: 30: 730-736.

17. Rutstein SO.DHS Wealth Index Construction. 2017. (Available from: https://www.dhsprogram.com/topics/wealth-inde $\mathrm{x} /$ Wealth-Index-Construction.cfm)

18. Merlo J, Yang M, Chaix B, Lynch J, Rastam L. A brief conceptual tutorial on multilevel analysis in social epidemiology: investigating contextual phenomena in different groups of people. J Epidemiol Community Health 2005: 59: 729-736.

19. QGIS Development Team. QGIS Geographic Information System. 2009. (Available from: http://qgis.org)

20. Adedokun ST, Uthman OA, Adekanmbi VT, Wiysonge CS. Incomplete childhood immunization in Nigeria: a multilevel analysis of individual and contextual factors. BMC Public Health 2017: 17: 236.

21. Rainey JJ, Watkins M, Ryman TK, Sandhu P, Bo A, Banerjee K. Reasons related to non-vaccination and under-vaccination of children in low and middle income countries: findings from a systematic review of the published literature, 1999-2009. Vaccine 2011: 29: 8215-8221.

22. Seck I, Faye A, Mbacké Leye MM et al. Measles epidemic and response in the region of Dakar (Senegal) in 2009. Sante Publique 2012: 24: 121-132.

23. Bekondi C, Zanchi R, Seck A et al. HBV immunization and vaccine coverage among hospitalized children in Cameroon,
Central African Republic and Senegal: a cross-sectional study. BMC Infect Dis 2015: 15: 267.

24. Wado YD, Afework MF, Hindin MJ. Childhood vaccination in rural southwestern Ethiopia: the nexus with demographic factors and women's autonomy. Pan Afr Med J 2014: 17 (Suppl 1): 9.

25. Bbaale E. Factors influencing childhood immunization in Uganda. J Health Popul Nutr 2013: 31: 118-129.

26. Nzioki JM, Ouma J, Ombaka JH, Onyango RO. Community health worker interventions are key to optimal infant immunization coverage, evidence from a pretest-posttest experiment in Mwingi. Kenya. Pan Afr Med J 2017: 28: 21.

27. Wiysonge CS, Uthman OA, Ndumbe PM, Hussey GD. Individual and Contextual Factors Associated with Low Childhood Immunisation Coverage in Sub-Saharan Africa: A Multilevel Analysis. PLoS One 2012: 7: e37905.

28. Ekouevi DK, Gbeasor-Komlanvi FA, Yaya I et al. Incomplete immunization among children aged 12-23 months in Togo: a multilevel analysis of individual and contextual factors. BMC Public Health 2018: 18: 952.

29. Okwaraji YB, Mulholland K, Schellenberg JRMA, Andarge G, Admassu M, Edmond KM. The association between travel time to health facilities and childhood vaccine coverage in rural Ethiopia. A community based cross sectional study. BMC Public Health 2012: 12: 476.

30. George K, Victor S, Abel R. Reliability of mother as an informant with regard to immunisation. Indian J Pediat. 1990: 57: 588-590.

31. Gareaballah ET, Loevinsohn BP. The accuracy of mother's reports about their children's vaccination status. Bull World Health Organ 1989: 67: 669-674.

32. Favin M, Steinglass R, Fields R, Banerjee K, Sawhney M. Why children are not vaccinated: a review of the grey literature. Int Health 2012: 4: 229-238.

33. O'Donnell O. Access to health care in developing countries: breaking down demand side barriers. Cad Saude Publica 2007: 23: 2820-2834.

34. Kibel M, Westwood T, Saloojee H. Child Health for All: A Manual for Southern Africa (5th edn), Oxford University Press: Cape Town, Republic of South Africa, 2013, 580.

\section{Supporting Information}

Additional Supporting Information may be found in the online version of this article:

Figure S1. Complete immunization of children aged 12-23 months at the time of the interview - Regional random effect estimates (DHS 2015-2017, $n=4955$ ).

Corresponding Author Sébastien Cortaredona, VITROME, IHU Méditerranée Infection, 19-21 bd Jean Moulin, 13005 Marseille, France. Tel.: +33413732412; E-mail: sebastien.cortaredona@ird.fr 